\title{
Editorial
}

\section{Introduction: God out of Mind}

\author{
Yiftach Fehige ${ }^{\mathbb{D}}$ \\ Institute for the History and Philosophy of Science and Technology, University of Toronto, \\ Toronto, ON M5S 1K7, Canada; yiftach.fehige@utoronto.ca
}

Received: 5 February 2020; Accepted: 14 February 2020; Published: 17 February 2020

This Special Issue of Religions is about the encounter between thought experiments and theology. Thought experiments are imagined scenarios of some experimental character that are used for various purposes, including the investigation into the nature of things. Theology is the study of God. The encounter between the two raises lots of intriguing questions: Does theology use thought experiments more or less often, or in different ways than, say, physics or philosophy? What are the defining characteristics of theological thought experiments, in contrast to philosophical, mathematical, historical, etc., thought experiments? What exactly can be achieved by means of thought experiments in theology? Does the use of thought experiments for cognitive purposes exhibit a reasonable trust in the abilities of the human mind, unaided by experience? And what about the theological assumptions that can be found in some thought experiments that are not about theological matters-where and why do these appear where they do? These, and many other exciting questions, are addressed by the original papers this Special Issue collects. It is not only that these papers offer highly original arguments that have been missing in the pertinent literature; they express yet unarticulated perspectives on a most intriguing topic.

Marco Buzzoni and Valentina Sovarjardo-two philosophers working in Italy-ask what theological thought experiments are, as opposed to thought experiments in the natural sciences. They find similarities, but also significant differences, between scientific and theological thought experiments. Their analysis is driven by an interpretation of Immanuel Kant's views of experiments and the a priori. Theological thought experiments can be compared to the kind of hypothetical reasoning that scientific practice displays. However, insofar as all thought experiments must be realizable in principle by operational and technological means in the real world, theological thought experiments (which lack this possibility) do not qualify as "genuine" thought experiments. All thought experiments must be realizable in principle by operational and technological means in the real world. Furthermore, the a priori reasoning they involve is very different than that which is involved in non-theological thought experiments. James R. Brown-a Canadian philosopher and prominent atheist, who pioneered the study of scientific thought experiments-submits for discussion an original thought experiment that features a deity in order to advance Platonism in philosophy of mathematics. Brown's thought experiment exemplifies the type of thought experiments that feature constitutively theological assumptions, although the subject matter is not theological. Medieval discussions about knowledge often assumed angels when investigating the nature of knowledge. And, between the 12th and 16th century, thought experiments facilitated the investigation into nature that paved the way for the rise of modern science. In this respect, Brown's thought experiment is not unusual. He is right to highlight the thought experiments that we find in the Leibniz-Clark Correspondence to argue that theological assumptions did play a major role in modern science, too. At the center of Brown's analysis is the notion of mathematical evidence. The established notion, he contends, is unnecessarily constrained by the accepted disciplinary standard of deductive proofs in mathematics. The invocation of the goddess Athena helps him to make the point that mathematics is like physics in that it discovers. In mathematics, however, inductive inferences are made from findings in the Platonic realm populated by abstract entities that are awaiting our discovery. Menachem Fisch—an Israeli historian of science 
and a Jewish philosopher-engages with Gulliver's Travels. He argues that it offers powerful thought experiments that target the philosophies of science of Francis Bacon and René Descartes in order to make room for the meaningful use of thought experiments in science and beyond. This is in and of itself of great philosophical significance, he argues, because Baconian empiricism and Cartesian rationalism are too narrow to capture the wide spectrum of kinds of scientific reasoning. And Fisch sees theological significance here, because the epistemology he finds advanced in Gulliver's Travels is claimed to resemble that of the Talmud. His discussion is rich in detail in its treatment of central passages of Gulliver's Travels and of examples from the Talmud. Ingrid Malm-Lindberg-a Swedish graduate student in theology-also touches on the most intriguing discussion of the relationship between literary fiction and thought experiments. She presents a deep analysis of Søren Kierkegaard's Fear and Trembling, with a clear focus on the explanatory role of thought experiments in that work. What she finds is an exemplar of what she creatively terms "Socratian Theology" to capture the dialectical nature of Kierkegaard's thinking at the intersection of philosophy and Christian theology. Her discussion touches, in significant detail, on the question of what the role of literary fiction is in theology, considering both Kierkegaard's work and the debate over literary cognitivism. The Canadian philosopher of science and religion, Travis Dumsday, is as adventurous as Brown and develops a thought experiment to advance a position outside the mainstream. He aims to challenge "methodological naturalism", as it is claimed to characterize the sciences. The topic of his discussion is near-death experiences. He argues that his thought experiment about the possible verification of such experiences will undermine methodological naturalism once realized, which he deems doable. Finally, Uwe Meixner-a German philosopher-explores the nature of board games to shed light on the indeterminism that he finds characteristic of the relationship between God and the world. His discussion commits him to the view that thought experiments are models. His analysis of board games feeds a metaphysical model that is to shed light on the central aspects of the analogy and their resemblance to the way God and humans relate to the world.

I am very much indebted to the seven colleagues whose work this issue features. I am also indebted to the journal Religions for inviting me to guest-edit this Special Issue and the many referees whose service was essential in the selection of all the submissions that were received with gratitude.

Conflicts of Interest: The author declares no conflict of interest.

(C) 2020 by the author. Licensee MDPI, Basel, Switzerland. This article is an open access article distributed under the terms and conditions of the Creative Commons Attribution (CC BY) license (http://creativecommons.org/licenses/by/4.0/). 